Antonio Tucci. Profesor titular por el Dipartimento di Scienze giuridiche de la Università di Salerno y enseña Filosofía del Derecho y Sociología del Derecho. Sus ámbitos de investigación son las transformaciones del derecho en la sociedad global, los espacios políticos, los procesos de subjetivización y dinámicas de inclusión y exclusión, los dispositivos del poder en la perspectiva del paradigma biopolítico gubernamental. Es autor de Individualità e politica (Napoli, 2002); Stabilizzazione e movimento. Una rilettura di Durkheim alla luce della globalizzazione (Napoli, 2003); Immagini del diritto. Tra fattualità istituzionalistica e agency (Torino, 2012).

Contacto: a.tucci@unisa.it 


\title{
TRANSFORMACIONES DEL PODER Y SUBJETIVACIONES POLÍTICO-JURÍDICAS
}

\author{
Antonio Tucci
}

Università degli Studi di Salerno

\section{TRANSFORMATIONS OF POWER AND POLITICAL-LEGAL SUBJECTIVATIONS}

DOI: $10.17450 / 150201$

Hoy día, la gobernanza global parece estar caracterizada y cruzada por constantes y enredados flujos de informaciones, capitales y personas frente a los cuales, no obstante perduren en su enunciación formal, se exige que las categorías y los instrumentos conceptuales tradicionales se vuelvan a considerar y semantizar. La racionalidad política y jurídica tradicional con su connotación unitaria, ordenada y universal ya no parece funcionar: en las prácticas efectivas de concretas relaciones de poder, contingentes e inmanentes -y por eso precarias e inestables-, los universales jurídicos (soberanía, sujeto, ciudadanía, etc.) se vuelven a elaborar en la base de lógicas que remiten a estrategias y técnicas de gobierno que exceden a las modalidades del orden, supuesto o por lo menos deseable, que había marcado el pensamiento político y jurídico hasta la segunda mitad del siglo pasado, en nombre de la reconstitución y neutralización de los conflictos y de la estabilidad de la forma. 
Aquella misma forma que evoca el orden, la unidad, la previsibilidad y la seguridad, hoy día sufre dificultades y aquella misma autorrepresentación se disuelve en una serie de representaciones que nacen de miles de facetas por medio de las cuales se manifiesta la red de la gobernanza, que difícilmente se puede desenmarañar. Estamos hablando, pues, de una serie de representaciones que se sobreponen pero que la una no excluye a la otra: no se trata de sustituir un modelo con otro, sino de poner de manifiesto la competencia de varios modelos y la imposibilidad de entender una realidad compleja y perturbada mediante formas preconstituidas. La forma -que ya no es coherente ni definida, y que no trasciende la realidad empírica -adquiere la movilidad de las formas-de-vida y se convierte en flexible y adecuada a los contextos de los que emerge y a los que se adecúa, reglamentándolos y adaptándolos a su vez.

Partiendo de esto, este número de la revista quiere interrogarse acerca de las posibles declinaciones del poder y de la subjetivización política y jurídica en la superposición e intersección de prácticas de gobierno entre concepciones soft y hard de la política y del derecho que si se consideraran bajo una perspectiva dicotómica -gobernanza como softness y modelo soberanista como hardness- quedarían demasiado ejemplificadas sin lograr explicar la complejidad de la situación.

En primer lugar, los artículos presentados se pueden enmarcar en el ámbito -directo (Saidel, Straehle, Carniglia) o implícito- de la gubernamentalidad que, como es notorio, Foucault relaciona con el largo proceso de difusión de poderes que compiten entre ellos y que son diferentemente legitimados. Se trata de un proceso, pues, en el que antes que todo está implicado el Estado mismo: tal como demuestra Foucault, a despecho de la autorrepresentación de la ciencia jurídica, las instituciones jurídicas y políticas siempre han actuado concretamente con otros poderes: el análisis de los dispositivos de gestión y las tecnologías de poder que el Estado ha adoptado cada vez a partir de la modernidad, pero remontando al pre-moderno, ponen de manifiesto aquel recoveco gubernamental detectado por Foucault en el largo proceso de "gubernamentalización del Estado". A raíz de su identificación exclusiva con la soberanía, el Estado reglamenta, gestiona y administra de forma gubernamental. De hecho, desde siempre el Estado ha tenido con otros sujetos - con las clases, las asociaciones, hasta llegar a los cuerpos intermedios- relaciones de distribución y de gestión de poderes que han obstaculizado la concentración del poder y la realización de las prerrogativas soberanas que revelan una aptitud a la negociación y a la mediación.

Y en la gobernanza esta capacidad gubernamental con toda su ambivalencia y opacidad se hace cada vez más evidente adquiriendo formas más radicales. Sin embargo, 
sería demasiado fácil e irénica una visión de un mundo gobernado por una red de relaciones sin confines y sin choques ultimativos; es importante admitir que la capacidad gubernamental de cruzar confines y crear otros más, que desarticulen aquella vocación a la unificación de pueblo, territorio y ordenamiento que caracterizaba a la soberanía moderna, de vez en cuando es puesta en tela de juicio y bloqueada; a veces es realmente contestada por la presencia de poderes soberanos que, por medio de la coerción y del uso legítimo de la fuerza, imponen la resolución legal de los conflictos. Así que desaparece aquella pretensión conceptual de la soberanía de considerar la unidad política como una condición de posibilidad de lo jurídico: a través de su propia acción, la gubernamentalidad lleva a áreas móviles de unidad y coherencia, capaces de crear reglas, aunque en una negociación material y concreta, momentáneas de las fuerzas, pero sin creer en la idea de un corte temporal entre los paradigmas que el mismo Foucault considera una separación entre "estatalización de la sociedad" y "gubernamentalización del Estado", entre soberanía y disciplinas por un lado y gubernamentalidad por el otro.

Hablamos, pues, de una doble racionalidad que remite a lógicas diferentes, la primera identitaria y legitimante, la segunda estratégica y económica, y que cruza entre sí decisiones soberanas y negociaciones gubernamentales, creando un ámbito desordenado, incoherente, pero claramente más real y concreto que cada representación formal y abstracta. En el ámbito de la sociedad neoliberal, la coerción y la imposición externa y heterónoma de la ley a individuos sometidos es puesta en tela de juicio por técnicas que se basan en individuos libres y capaces de autodeterminarse, en una lógica dirigida al empowerment y al agency, entre autoafirmación y gestión del riesgo y de la seguridad de los individuos como tales y de las poblaciones (Arienzo).

Todo esto implica que se vuelva a considerar, por un lado, la normatividad jurídica y social y, por otro lado, las formas de subjetivación que, en lugar de caracterizarse mediante dispositivos de inclusión y exclusión, lo hacen en términos de inclusividad tendencial de todos, basada en criterios de selección y adaptación de las heterogeidades funcionantes. Por este aspecto se han interesado muchos autores de este número de la revista, aunque desde perspectivas diferentes.

Antes que todo la ley: general, abstracta, previsible y coherente. Se sigue destacando que la ley está perdiendo su centralidad, basada en la normatividad trascendente del mando soberano, en provecho de una forma normativa que se hace inmanente, particular, concreta. Esta Ley cede el paso a la norma, una normatividad adecuada al caso, de ahí que las cuestiones particulares encuentren su autorreglamentación inmanente, 
que emerge de la particularidad y que no se puede generalizar. Y es precisamente a estas formas de normatividad inmanente que se refieren las autoridades hoy emergentes y dominantes, para desengancharse de la dependencia de la autoridad formal jerárquicamente legitimada, para eludirla, para competir con ella, o bien para interpretarla a la luz de intereses específicos (Marotta).

Nos encontramos ante un radical viraje respecto de la norma, en el ámbito de una lógica inmanentística, y a pesar de eso normativa. La vida -entendida como la concreta y heterogénea realidad social que solo en abstracto podemos homogeneizar- produce normas durante su continua y multiforme adaptación y producción. La racionalidad gubernamental actúa incorporándose y adaptándose a esta regla ínsita en las cosas y emergente de ellas, una racionalidad que laisse faire: la impronta ideológica y naturalizada del neoliberalismo se destaca en la constante referencia a la espontaneidad de la autorreglamentación del ser.

Está claro que los espacios de acción de los rayos del poder se ensanchan y se integran recíprocamente a niveles diferentes y según trayectorias plurales, pero siempre en un ámbito de gestión y de gobierno, menos directo, menos explícito pero más eficaz, difusivo, global: tal como destaca Foucault, la norma no excluye, no rechaza, sino interviene y transforma. Para sintetizar, podríamos decir que en la gobernanza, en donde las prácticas coinciden con las formas, normatividad y normalización se sobreponen, sin ninguna posibilidad de solución. La dimensión descriptiva y efectual de la norma se confunde con la prescriptiva, y se configura como un dispositivo interno a su mismo campo de aplicación. La percepción de estas desviaciones hacia la inmanencia induce a reflexionar sobre el poder como expresión de ámbitos heterogéneos y diferentes, que atañen a una red de juegos lingüísticos y esferas diferenciadas (Marzocchi), o a pensar en cómo en la teoría social la normatividad se define como conexión recíproca entre singularidades y prácticas y contextos específicos, con importantes repercusiones en la dimensión jurídica (Croce). Además, la misma teoría jurídica se ha ocupado de las formas y de las instituciones (antes que todo el soft law) que remiten a una concepción horizontal y participativa del derecho (Greco).

Igualmente, el carácter productivo y relacional de la gubernamentalidad, que induce a juntar técnicas de subjetivización y sometimiento, confirma la naturaleza procesual y generativa del poder. De hecho, los individuos adquieren de forma ambivalente el estatus de sujetos libres y autónomos y, al mismo tiempo, sometidos a las prácticas discursivas dominantes, las modifican y las adaptan cada vez dependiendo de sus específicas y particulares formas de vida; así que en la fase neoliberal la racionalidad del poder no 
remite a la norma inclusiva/excluyente, sino a técnicas y prácticas de inclusividad. Nadie está excluido en principio, sino solo se puede formar parte selectivamente en la base de criterios que remiten a los objetivos específicos del gobierno. Una inclusión tendencial de todos no se basa en exclusiones o está legitimada por estas, sino que quizá lleve a aquellas exclusiones, a menudo en la base de una heterogénesis de los fines: barreras, confines que, no obstante sean flexibles y permeables, no solo de forma ambivalente en toda su materialidad y obstinación, sino también simbólicamente, escogen a quien debe quedarse afuera y a quien debe ser incluido, marcando diferencias y exclusiones. El tema de los derechos y de las identidades se resuelve en formas de agregación de los individuos en grupos (mejor dicho, poblaciones) que se asemejan por rasgos gobernables de forma similar y potencialmente capaces de autogobierno, pero estas dinámicas de subjetivación y sometimiento generan al mismo tiempo resistencias y contraconductas y definen al individuo y a los grupos dependiendo de las desviaciones de la norma que ellos mismos ponen en práctica, como en el caso de la experiencia de la teología de la liberación en América Latina (Colucciello-Scocozza).

Por otra parte, la lógica inclusiva selectiva parece funcionar en la permanencia de las formas de la ciudadanía y de la identidad, empleadas estratégicamente para alcanzar finalidades concretas, bajo formas de mediaciones y transacciones específicas y concretas, con evidentes consecuencias de intraducibilidad en términos de universalidad y de reconocimiento de los derechos humanos. De hecho, relacionar entre sí una subjetividad universal con la categoría de humanidad, de naturaleza o esencia del hombre significa producir formas de objetivación de la alteridad y criterios que justo cuando se den como fundamentados universalmente, revelan dispositivos de selección y marginalización. Si no eliminan, los derechos humanos por lo menos transforman $y$, transformando, seleccionan y normalizan: cuando persiguen el objetivo de derrumbar barreras, eliminar distancias, superar o valorizar, dependiendo de los casos, las diferencias, marcan límites, confines (identitarios, culturales) que se pueden superar muy difícilmente, tal vez haciéndoles pagar un precio muy alto a los que piden ser incluidos, con consecuencias muy graves para el experto de derecho positivo en el ámbito del reconocimiento y de la tutela jurídica de subjetividades diferentes con respecto a la norma (Ivone).

En definitiva, podemos decir que las proclamaciones de los derechos implican la afirmación de un absoluto (el hombre, la persona) que legitima el gobierno selectivo del ser, con el riesgo muy elevado de que la enfatización del carácter prescriptivo y universal de los derechos pueda legitimar poderes fuertes y graves desigualdades (Baccelli). 
Hacer hincapié en las categorías de humanidad y de persona revela un supuesto universalismo que se traduce inevitablemente en formas esencialistas, inclusivas y excluyentes de la identidad, mediante modalidades y estrategias indiferentemente soft y hard.

Se ha intentado deconstruir este proceso, pero sobre todo en el ámbito postcolonial ha surgido la instancia que llamaríamos eurocéntrica de todo discurso que se quiera autoproclamar en términos de universalidad “objetiva”. En particular, las páginas que Gustavo Gozzi en su libro Umano non umano. Intervento umanitario, colonialismo, primavere arabe-que vamos a presentar en este número con las contribuciones de Pietro Costa, Stefania Negri y Stefano Pietropaoli- dedica a las formas de inferiorización y objetivación de la alteridad producidas por la categoría previsiblemente universal y abstracta de humanidad parecen ser particularmente evocadoras.

En la reconstrucción de la compleja y articulada relación entre colonialismo e intervención humanitaria, conformemente a las tesis de Koskenniemi, Gozzi subraya que cualquier forma de universalismo o solidaridad basada en presuposiciones humanitarias no es otra cosa sino la revelación de técnicas hegemónicas perseguidas para que una parte pudiera controlar el resto del mundo. Así que el autor individua -en la representación y construcción de la naturaleza humana como criterio de clasificación y esencialización del colonizado- una serie de coordenadas que logran hacer emerger las contradicciones y los límites del planteamiento eurocéntrico. La psicología colonial que construye la imagen del colonizado a partir de "una diferente naturaleza humana", o la revelación por parte de Fanon del rasgo ideológico y violento del concepto de humanidad hasta la asimilación del colonizado y la negación de su propia cultura, aclaran el doble valor ínsito en el dispositivo de la inclusión del que hablábamos antes: tal como nos dice Althusser, el humano implica una ideología selectiva, que opera por medio de la separación y la jerarquización; y separar y jerarquizar significa excluir o englobar, eliminar o asimilar.

Muchas veces, en la obra Peau noire, masques blancs, Fanon afirma: "Je voulais tout simplement être un homme parmi d'autres hommes", o bien "Le Noir veut être Blanc. Le Blanc s'acharne à réaliser une condition d'homme", y esto prueba que la reivindicación de particularidades y pertenencias presentadas como universales, biológica y culturalmente definidas y por eso parciales, corre el riesgo de traducirse inevitablemente en separación y exclusión, claro está. Solo partiendo de la connotación del sí como otro inferiorizado, el colonizado -en una dialéctica de subjetivación y sometimiento, dentro de prácticas y estrategias de resistencia, contraconducta y adaptación- puede volver a 
elaborar y adaptar la norma (humanidad, persona, derechos) a su propia forma de vida: "Je décidai, puisqu'il m’était impossible de partir d'un complexe inné, de m’affirmer en tant que NOIR. Puisque l'autre hésitait à me reconnaître, il ne restait qu'une solution: me faire connaître".

Traducción del italiano de M. Colucciello 